\title{
CAPÍTULO 03: DESENVOLVIMENTO DE BROWNIE ADICIONADO DE BAGAÇO DE MALTE
}

\section{CHAPTER 03: DEVELOPMENT OF BROWNIE ADDED MALT BAGASSE}

\author{
Isabella Maciel Costa ${ }^{1}$; Amanda Nayara Abreu Silva ${ }^{2}$; Franciele Marques de Oliveira ${ }^{3}$; Leonara \\ Martins Viana ${ }^{4}$; Kennedy Borges Oliveira ${ }^{5}$
}

\begin{abstract}
Resumo
O brownie é um bolo doce que pode possuir cobertura de chocolate e ser acrescido de manteiga de amendoim, castanha, pedaços de chocolate e outros recheios. O bagaço de malte é o principal subproduto da fabricação de cervejas e por possuir um alto conteúdo de fibras e de resíduos de proteínas, possui potencial de uso em produtos de panificação. O objetivo foi elaborar um brownie adicionado de bagaço de malte e avaliar suas características físico-químicas e sensoriais. Foi elaborada uma formulação com bagaço de malte seco e triturado. Foram realizadas análises de $\mathrm{pH}$, umidade, acidez total titulável, cor, análise sensorial e elaboração da informação nutricional. Os valores $\mathrm{pH}$ e acidez encontrados foram de 5,89 e 1,90\%, caracterizando o produto como de baixa acidez. O teor de umidade foi de 13,2\%, resultado inferior a relatados na literatura. Os resultados da análise sensorial variaram de 7,1 a 8,3 para os atributos indicando que os avaliadores classificaram o brownie entre "gostei moderadamente" e "gostei muito". O valor de intenção de compra foi de 4,15, assinalando que a maioria provavelmente compraria o produto. Desse modo, concluiu-se que é possível elaborar um brownie com bagaço de malte e obter boas características tecnológicas e sensoriais.
\end{abstract}

Palavras-Chaves: Bolo, Fibra de malte, Resíduo, Cerveja.

\begin{abstract}
The brownie is a sweet cake that can have chocolate topping and can be added of peanut butter, chestnut, chocolate pieces and other fillings. The malt bagasse is the main by-product of beer brewing and because it has a high content of fibers and protein residues, it has the potential to be used in bakery products. The objective was to develop a brownie added malt bagasse and evaluate its physical-chemical and sensory characteristics. A formulation with dried and crushed malt bagasse has been developed. Analyses of $\mathrm{pH}$, moisture, total titratable acidity, color, sensory analysis and nutritional information were performed. The $\mathrm{pH}$ and acidity values found were 5.89 and $1.90 \%$, characterizing the product as low acidity. The moisture content was $13.2 \%$, a lower result than reported in the literature. The results of the sensory analysis ranged from 7.1 to 8.3 for the attributes indicating that the evaluators classified the brownie between "liked moderately" and "liked a lot". The purchase intention value was 4.15 , indicating that most of the evaluators would probably buy the product. Therefore, it was concluded that it is develop to prepare a brownie with malt bagasse and obtain good technological and sensory characteristics.
\end{abstract}

Keywords: Cake, Malt fiber, Residue, Beer.

\footnotetext{
${ }^{1}$ Engenharia de Alimentos, Universidade Feral de São João del Rei, bellamaciel@hotmail.com

${ }^{2}$ Engenharia de Alimentos, Universidade Feral de São João del Rei, amandanayara71@gmail.com

${ }^{3}$ Engenharia de Alimentos, Universidade Feral de São João del Rei, francielemarques12@ hotmail.com

${ }^{4}$ Engenharia de Alimentos, Universidade Feral de São João del Rei, leonaravianna@ hotmail.com

${ }^{5}$ Engenharia de Alimentos, Universidade Feral de São João del Rei, k.borges02.kb@gmail.com
} 


\section{Introdução}

As tendências atuais do mercado alimentício estão relacionadas com a conveniência, autenticidade, prazer e saúde (ORSINE; MARTINS; LIMA, 2016). Para os produtos de panificação, os bolos têm cada vez mais destaque no consumo e comercialização no país. Assim, diversas empresas se adaptaram visando diversificar os bolos, texturas, sabores, recheios e produtos semelhantes, como muffins, cupcakes e brownies (SIMON, 2014).

O brownie é um produto de origem americana, classificado como sobremesa, e se caracteriza como um bolo doce, pequeno, que pode possuir uma cobertura de chocolate e ser acrescido em sua parte interna de manteiga de amendoim, castanha, pedaços de chocolate e outros tipos de recheios (COSTA et al., 2015).

A massa do bolo ou de um produto similar é considerada uma emulsão de óleo em água, com uma fase aquosa contendo os ingredientes dissolvidos ou dispersos e com bolhas de ar aprisionadas na fase gordurosa. A incorporação de ar na massa tem influência no volume do bolo, mas para o brownie não se necessita de uma grande incorporação de ar (SIMON, 2014). A utilização de farinhas, ricas em fibras, está sendo usada na elaboração de produtos de panificação e massas alimentícias, ampliando a oferta de produtos com elevado teor de fibra, tanto para os consumidores sadios quanto para aqueles que apresentam algumas doenças crônicas não transmissíveis (QUEIROZ et al., 2016). O conhecimento sobre a importância das fibras alimentares na alimentação devido aos seus efeitos fisiológicos e metabólicos tem levado a um maior interesse do público e, consequentemente, a indústria a desenvolver novos alimentos enriquecidos com fibras (ALMEIDA, 2006).

O aproveitamento de subprodutos agroindustriais tem se mostrado uma grande oportunidade para a indústria de alimentos, visto que atende à demanda de utilização das matérias-primas de forma total, promove agregação de valor perdido e uso sustentável dos resíduos, diminuindo os impactos ambientais que possam causar, além de reduzir custos. Dessa forma, estes resíduos podem ser utilizados como ingredientes para desenvolver um novo produto como alternativa de fonte nutricional (COSTA FILHO et al., 2017; CARVALHO, 2019).

O bagaço ou fibra de malte é o principal subproduto proveniente do processamento inicial da fabricação de cervejas (representa aproximadamente $85 \%$ dos subprodutos totais), sendo gerado de 14 a $20 \mathrm{~kg}$ a cada 100 litros de cerveja produzida, e está disponível em todos os meses do ano, em altas quantidades e a um custo acessível. Ele é composto pela casca da cevada malteada e é resultado do processo de obtenção do mosto, pela fervura do malte moído, que após a filtração, origina este subproduto. Assim, é constituído tanto por restos de casca e 
polpa de malte como dos grãos do adjunto, como milho e trigo (CORDEIRO; EL-AOUAR; GUSMÃO, 2012; PADIA, 2018). A extensa produção anual de cerveja no país, em torno de 8,5 bilhões de litros, fornece uma grande quantidade deste subproduto (MATTOS, 2010).

Esse subproduto é um material lignocelulósico, constituído de 35\% de hemicelulose, $20 \%$ de celulose, $10 \%$ de lignina e 10\% de gorduras (MATTOS, 2010). Ele contém 20 a 30\% de proteínas, 70 a $80 \%$ de fibras, $1,2 \%$ de mono e diácidos fenólicos e é fonte de vitaminas do complexo B, logo, tem um elevado valor nutritivo (HERNÁNDEZ et al., 1999; PADIA, 2018). No entanto, essa composição pode variar de acordo com o tipo de cevada utilizada, as condições de maltagem e mosturação e a quantidade e tipo de adjunto adicionado (SANTOS; DINHAM, 2006). Pelo fato de que o bagaço de malte possui um elevado teor de umidade, valor nutricional e presença de resíduos de açúcares fermentescíveis, ele é susceptível à contaminação por microorganismos, principalmente por bolores, e deve ser retirado da cervejaria o mais rápido possível. Sendo assim, deve-se utilizar técnicas de conservação como a secagem, o congelamento e a adição de conservantes para aumentar sua vida de prateleira (PADIA, 2018).

Devido ao fato de apresentar um alto conteúdo de compostos orgânicos e de alto valor nutricional, o bagaço de malte precisa passar por um tratamento antes de ser descartado para evitar danos ambientais. Sendo assim, o seu aproveitamento em outros processos ou produtos é extremamente vantajoso, pois obtém-se maior valor agregado devido ao uso para fins mais nobres e apresenta-se como uma alternativa economicamente viável para destinação dos resíduos (CARVALHO, 2019).

Também pelo fato do bagaço de malte possuir um alto conteúdo de fibras e de resíduos de proteínas e açúcares, ele se torna um subproduto com potencial de uso em produtos de panificação, como bolos, biscoitos e pães de forma, em que a adição de fibras oferece efeitos benéficos, do ponto de vista nutricional e funcional, ao consumidor (CORDEIRO; ELAOUAR; GUSMÃO, 2012). Dessa forma, ao utilizar esse subproduto no ramo de panificação, espera-se uma maior valorização do resíduo, aumentando seu valor agregado e trazendo benefícios à indústria alimentícia (MATTOS, 2010).

Nesse sentido, o objetivo deste trabalho foi desenvolver uma formulação de brownie com apelo nutricional diferenciado pela adição de bagaço de malte, um subproduto industrial rico em fibras, de modo a aproveitá-lo na fabricação de um alimento. Além disso, objetivouse avaliar seu teor de umidade, $\mathrm{pH}$, acidez, cor e suas características sensoriais.

\section{Material e Métodos}

Elaboração e teste de formulação do brownie 
Todos os ingredientes utilizados foram adquiridos no comércio local da cidade de Sete Lagoas - Minas Gerais e estavam dentro da data de validade. O bagaço de malte foi doado por uma cervejaria artesanal da cidade para a condução do experimento e estava congelado no momento da recepção. O bagaço foi previamente seco em estufa com circulação de ar a 40 ${ }^{\circ} \mathrm{C} / 48$ horas e, em seguida, triturado e peneirado para utilização nas formulações.

Foram desenvolvidas duas formulações para teste (Tabela 1): uma sem adição de cerveja comercial (F1) e outra com a presença desta bebida $(\mathrm{F} 2)$.

Tabela 1. Formulações dos brownies com adição de bagaço de malte.

\begin{tabular}{lcc}
\hline \multicolumn{1}{c}{ Ingrediente } & F1 (\%) & F2 (\%) \\
\hline Chocolate meio amargo bem picado & 12,1 & 10,4 \\
Margarina sem sal & 17,5 & 15,1 \\
Bagaço de malte & 5,4 & 4,6 \\
Cerveja comercial Pilsen teor alcoólico 4,6\% vol. & 0 & 13,9 \\
Ovos & 13,5 & 11,6 \\
Açúcar & 33,7 & 29,0 \\
Farinha de trigo sem fermento & 10,8 & 9,3 \\
Sal & 0,5 & 0,5 \\
Cacau em pó & 2,4 & 2,1 \\
Chocolate meio amargo em pedaços finos (ralado) & 4,0 & 3,5 \\
\hline F1 - formulação de brownie sem cerveja comercial Pilsen e F2 - formulação de brownie contendo cerveja \\
comercial Pilsen. & &
\end{tabular}

Para a produção do brownie, o preparo foi baseado no método descrito por Queiroz et al. (2016) com algumas adaptações. Em primeiro lugar, derreteu-se o chocolate meio amargo bem picado juntamente com a margarina em banho-maria e reservou-se. Os ovos foram batidos até ficarem volumosos. Em seguida, adicionou-se açúcar, farinha de trigo sem fermento, sal, cacau em pó, chocolate meio amargo ralado, bagaço de malte e adicionou-se o preparo reservado. $\mathrm{O}$ bagaço de malte foi previamente seco em estufa a $40{ }^{\circ} \mathrm{C}$ com circulação de ar por 48 horas e, em seguida, triturado em mixer e peneirado. Na formulação F2, procedeu-se da mesma forma adicionando ao final a cerveja. Posteriormente, colocou-se cada mistura em uma assadeira untada com óleo e polvilhada com cacau em pó e assou-se a $180^{\circ} \mathrm{C}$ por 40 minutos. Antes de desenformar, deixou-se resfriar por 1 hora.

\section{Análises físico-químicas}

Foram realizadas análises de $\mathrm{pH}$, umidade e acidez total titulável conforme metodologias descritas pelo Instituto Adolfo Lutz (2008), em triplicata.

Para a avaliação da cor, também realizada em triplicata, utilizou-se um colorímetro portátil 
(Minolta Chroma meter CR-210), calibrado previamente e no sistema de cor CIELAB, em que os valores de L* (luminosidade/brilho) variam do preto ao branco ( 0 a 100), os valores do croma $a^{*}$ variam do verde $\left(-a^{*}\right)$ ao vermelho $\left(+a^{*}\right)$ e os valores do croma $b^{*}$ variam do azul $\left(-b^{*}\right)$ ao amarelo $\left(+b^{*}\right)$.

\section{Análise sensorial e pesquisa de mercado}

O teste foi desenvolvido no Laboratório de Análise Sensorial do Departamento de Engenharia de Alimentos (DEALI) da Universidade Federal de São João del Rei, campus Sete Lagoas (UFSJ-CSL). Os materiais necessários para preparação das amostras foram obtidos em comércio local da cidade de Sete Lagoas.

Para a análise sensorial, utilizou-se o teste de aceitação e de intenção de compra. A análise foi conduzida em cabines individuais utilizando luz branca e a melhor formulação foi analisada por 68 avaliadores não treinados, com idade acima de 18 anos e vinculados à UFSJCSL (estudantes, técnicos e professores). Antes da análise, todos os avaliadores assinaram o Termo de Consentimento Livre e Esclarecido (TCLE). A amostra foi identificada com três números aleatórios, servida em pratos descartáveis numa bandeja contendo um copo descartável com água e uma ficha de avaliação. Na ficha, foram analisados os atributos de cor, aroma, sabor, textura e impressão global por meio de uma escala hedônica estruturada de 9 pontos com as opções variando de "desgostei extremamente" (1) a "gostei extremamente" (9).

Para o teste de intenção de compra, foi utilizada uma escala estruturada de 1 a 5 com as opções variando de "certamente não compraria" (1) a "certamente compraria" (5). Após a análise sensorial, foi aplicada uma pesquisa de mercado abordando a frequência de consumo de brownie e de produtos adicionados de fibra, se o avaliador já havia consumido algum produto contendo subproduto da produção de cerveja, se era consumidor de cerveja, se consumia cerveja artesanal, se a adição de fibras influencia no momento da compra e sugestões de melhoria (Figura 1).

O grau de aceitação foi quantificado de acordo com a média das respostas e o índice de aceitabilidade foi calculado de acordo com a Equação 1 (SILVA et al., 2017):

$$
\mathrm{IA}(\%)=\mathrm{A} \times 100 / \mathrm{B}
$$

(Equação 1)

Onde:

$\mathrm{A}=$ nota média obtida para $\mathrm{o}$ atributo;

$\mathrm{B}=$ nota máxima dada ao atributo. 
Figura 1. Pesquisa de mercado aplicada após a realização da análise sensorial.

1. Com que frequência você costuma consumir brownie?

( ) Nunca ( ) Quase nunca ( ) As vezes ( ) Quase sempre ( ) Sempre

2. Você já consumiu algum produto contendo subproduto da produção de cerveja (malte)?

$$
\text { ( ) Sim ( ) Não }
$$

3. Você é consumidor de cerveja?

$$
\text { ( ) } \operatorname{Sim} \text { ( ) Não }
$$

Se sim, você tem o costume de consumir cerveja artesanal?

$$
\text { ( ) } \operatorname{Sim} \text { ( ) Não }
$$

4. Com que frequência você costuma consumir produtos adicionados de fibras?

( ) Nunca ( ) Quase nunca ( ) As vezes ( ) Quase sempre ( ) Sempre

5. A adição de fibras no produto influencia no momento de compra?

$$
\text { ( ) } \operatorname{Sim} \text { ( ) Não }
$$

6. O que você acha que poderia melhorar no produto?

Fonte: Própria (2020).

\section{Informação Nutricional}

Para elaboração da tabela nutricional do brownie, seguiu-se os passos descritos no Manual de Rotulagem Nutricional Obrigatória - Manual de Orientação às Indústrias de Alimentos da Agência Nacional de Vigilância Sanitária (ANVISA, 2005) com o auxílio de uma planilha do Excel para realizar os cálculos. A porção foi definida de acordo com a $\operatorname{RDC~}{ }^{\circ} 359$, de 23 de dezembro de 2003 (BRASIL, 2003).

\section{Resultados e Discussão}

\section{Teste de formulação}

As características sensoriais do produto obtido com a formulação F1 (sem adição de cerveja) não foram as esperadas, uma vez que houve um crescimento inicial exagerado da massa no forno seguido de redução do volume (murchamento). Além disso, o produto ficou ressecado, ou seja, não apresentou a consistência fofa esperada para o brownie. Já a formulação F2 (com adição de cerveja) apresentou crescimento e consistência característicos de brownie e, portanto, foi a formulação selecionada para as análises físico-químicas e sensoriais. 


\section{Análises físico-químicas}

Os resultados de $\mathrm{pH}$, acidez total titulável, umidade e cor podem ser observados na Tabela 2.

Tabela 2. pH, acidez total titulável, umidade e cor das amostras de brownie.

\begin{tabular}{ccc}
\hline Parâmetro & Resultado \\
\hline $\mathrm{pH}$ & & $5,89 \pm 0,03$ \\
Acidez total titulável $(\%)$ & $1,90 \pm 0,03$ \\
Umidade $(\%)$ & & $13,2 \pm 0,25$ \\
& $\mathrm{~L}^{*}$ & $30,51 \pm 1,23$ \\
Cor & $\mathrm{a}^{*}$ & $7,90 \pm 0,19$ \\
& $\mathrm{~b}^{*}$ & $11,01 \pm 0,15$
\end{tabular}

Fonte: Própria (2020).

Conforme o valor de $\mathrm{pH}$, os alimentos podem ser divididos em: alimentos de baixa acidez $(\mathrm{pH}>4,5)$, alimentos ácidos ( $\mathrm{pH}$ entre 4,0 e 4,5) e alimentos muito ácidos $(\mathrm{pH}<4,0)$. Dessa forma, percebe-se que o produto desenvolvido é classificado como de baixa acidez, pois o valor de $\mathrm{pH}$ encontrado foi de 5,89. Esta faixa favorece o crescimento de diversas bactérias, bolores e leveduras, pois encontra-se no seu ponto ótimo de crescimento. Este $\mathrm{pH}$ em torno da neutralidade torna o meio propício para micro-organismos, sejam eles patogênicos ou deteriorantes (FRANCO; LANDGRAF, 1996; MOURA; MOURA, 2014). Sendo assim, técnicas para aumentar a vida útil do produto deveriam ser utilizadas. Um bom método de armazenamento e embalagem é fundamental para garantir maior vida de prateleira a um produto. As embalagens multicamadas/laminadas se caracterizam como uma boa barreira à umidade, gases, aromas e à luz e poderiam ser uma boa alternativa para acondicionamento do produto elaborado. Além disso, a adição de um agente conservante poderia ser considerada.

No estudo de Orsine, Martins e Lima (2016) foram elaboradas duas formulações de brownie de chocolate com ingredientes dietéticos, light e não dietéticos e estas continham propionato de sódio e sorbato. Eles encontraram valores de pH de 6,29 e 7,34 para as duas formulações desenvolvidas, que são resultados superiores aos obtidos neste trabalho, mas que também se encontram em uma faixa que favorece o crescimento de micro-organismos.

O pH é um valor que expressa o ácido dissociado, já a acidez titulável expressa a quantidade do ácido presente. A determinação da acidez total em alimentos é bastante importante tendo em vista que através dela, pode-se obter dados valiosos na apreciação do processamento e do estado de conservação dos alimentos, além disso, pode-se afirmar que há uma relação inversamente proporcional entre estes parâmetros, pois quanto menor o $\mathrm{pH}$, maior 
a acidez encontrada (MOURA et al., 2014). Dessa forma, foi possível confirmar a relação pH e acidez, visto que o valor de acidez encontrado foi baixo o que corrobora o $\mathrm{pH}$ mais elevado.

No presente estudo, o brownie apresentou um teor de umidade de 13,2\%, o que representa um baixo teor. A Resolução CNNPA n¹2 de 1978 (BRASIL, 1978) determina um valor máximo de $15 \%$ de umidade para produtos à base de cereais. Dessa forma, o brownie elaborado atende ao estabelecido nessa legislação.

Orsine, Martins e Lima (2016) encontraram valores de 22,68\% e 24,95\% em suas formulações, que são superiores aos obtidos neste trabalho. Simon (2014) ao avaliar as características físico-químicas de brownie com farinha de arroz e trigo sarraceno obteve um teor de umidade de 23\%. Já Queiroz et al. (2016) ao avaliar três formulações de brownies produzidos a partir de farinha de coco e farinha de arroz, encontrou teores de umidade que variaram de $16,53 \%$ a $22,98 \%$.

Na formulação do brownie estudado, utilizou-se maior concentração de farinha de trigo em relação ao bagaço de malte. Panzarini et al. (2014) encontraram maiores teores de umidade em formulações de bolo elaboradas com maior porcentagem do bagaço, portanto, com mais fibra alimentar. Isso se justifica pela propriedade das fibras de reterem e manterem água em sua estrutura durante o processo de cocção, ou seja, há uma elevação na umidade de produtos à medida que o teor de fibras é aumentado. Além disso, o tempo de forneamento também pode influenciar no teor de umidade, visto que quanto maior o tempo de forneamento, maior a evaporação de água e, consequentemente, menor o teor de umidade.

Em relação aos parâmetros de cromaticidade $\left(a^{*}\right.$ e $\left.b^{*}\right)$, foi possível observar que a amostra se apresentou nas regiões vermelha e amarelo já que a leitura do colorímetro demonstrou valores positivos para estas coordenadas. Panzarini et al. (2014) menciona em seu trabalho que a combinação dos cromos positivos $a^{*}$ e $b^{*}$ resulta da cor marrom, coloração característica de produtos desenvolvidos com chocolate e seus derivados. Quanto ao parâmetro de luminosidade $\left(\mathrm{L}^{*}\right)$, as amostras foram consideradas escuras, já que na escala de 0 a 100 apresentaram valores abaixo de $50\left(\mathrm{~L}^{*}<50\right)$. Ademais, outros fatores podem ter afetado a coloração dos brownies, como a presença de açúcares e ovos, assim como o calor, que acelera reações de caramelização e de Maillard, levando ao escurecimento progressivo da crosta e do miolo (PANZARINI et al., 2014).

A coloração dos alimentos representa um dos atributos mais importantes observados pelos consumidores podendo intervir na decisão de compra, bem como representa o indicador de pigmentos durante o escurecimento não enzimático e o processo de caramelização (SCHMIELE et al., 2011). Logo, para os brownies, o consumidor espera uma coloração marrom 
escuro, pois é feita uma associação com a presença do chocolate. Na Figura 2, é possível observar a coloração obtida no brownie elaborado.

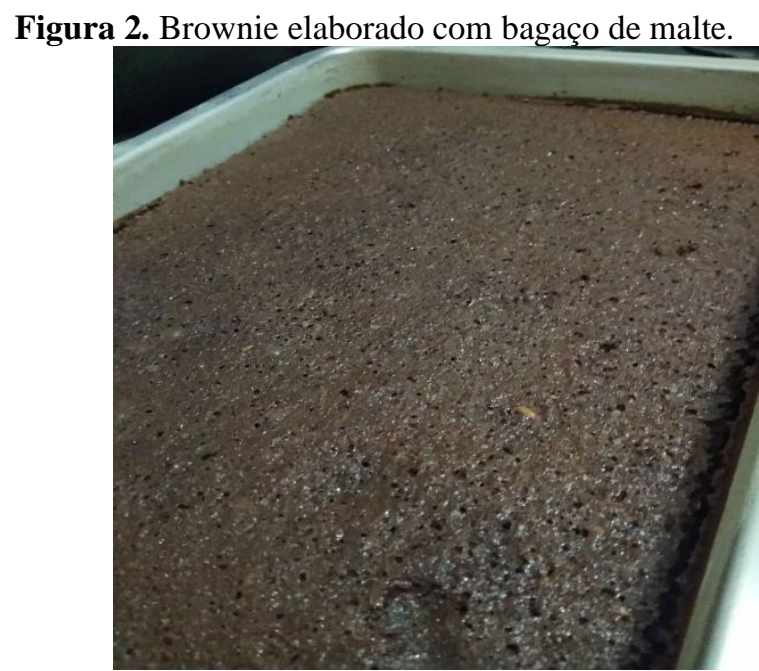

Fonte: Própria (2020)

\section{Análise sensorial}

Os resultados da média de aceitação sensorial para cada parâmetro e o índice de aceitabilidade (IA) estão descritos na Tabela 3.

Tabela 3. Média das notas de aceitação sensorial para cada atributo e índice de aceitabilidade das amostras de brownie com fibra de malte.

\begin{tabular}{lcc}
\hline \multicolumn{1}{c}{ Atributo } & Média de aceitação & Índice de aceitabilidade (\%) \\
\hline Impressão global & 7,9 & 87,6 \\
Sabor & 8 & 100 \\
Textura & 7,1 & 78,6 \\
Aroma & 7,9 & 88,2 \\
Cor & 8,3 & 92,8 \\
\hline \multicolumn{3}{c}{}
\end{tabular}

Pôde-se observar que a amostra apresentou resultados que variaram de 7,1 a 8,3 para os atributos avaliados indicando que os provadores classificaram o brownie entre "gostei moderadamente" e "gostei muito". Dentre os atributos, o que obteve uma menor média de aceitação $(7,1)$ foi a textura.

A textura foi um dos pontos mais citados para melhoria na pesquisa de mercado, uma vez que as fibras estavam ligeiramente aparentes. Isso provavelmente se deve ao fato de que o processo de refinamento do bagaço de malte foi artesanal (trituração em mixer e em peneira comercial) e a percepção sensorial das fibras ficou mais evidente. Contudo, considerando-se um processamento industrial, em que o bagaço passaria por etapas refinadas de trituração e 
peneiramento ou ainda poderia ser transformado em farinha, a percepção sensorial das fibras poderia ser diminuída e haver uma aceitação ainda maior.

Com relação à intenção de compra, o valor médio encontrado foi de 4,15 o que indica que a maioria dos provadores provavelmente comprariam o produto. Dessa forma, este poderia ser um bom nicho de mercado para se investir. Além da facilidade de preparo e da boa aceitação, o brownie é um tipo de inovação gourmet que tem sido a causa de sucesso de vários negócios, principalmente as confeitarias e, logo, uma ótima atividade para empreender (KALIL, 2020; LISBOA, 2020; SANTIAGO, 2020; SEBRAE, 2020).

Para que o IA indique boa aceitação, os atributos sensoriais devem apresentar um valor igual ou maior a 70\% (DUTCOSKY, 2011). Desse modo, pôde-se perceber que a amostra obteve valores de IA superiores a $70 \%$ para todos os atributos, sendo assim um resultado satisfatório. $\mathrm{O}$ atributo que apresentou maior IA foi o sabor, enquanto o de menor foi a textura. No trabalho de Mattos (2010), foi elaborado um pão adicionado de $30 \%$ de fibras a partir do bagaço de malte e na análise sensorial, os valores médios para os atributos mostraram boa aceitação, ficando entre 7,2 e 8 e os índices de aceitabilidade para todos os atributos foram superiores a 70\%, que são resultados semelhantes aos encontrados no presente estudo. Panzarini et al. (2014) encontraram em suas duas formulações de bolo de mel enriquecido com fibras do bagaço de malte índices de aceitabilidade acima de $80 \%$ para todos os atributos. Dalmolin et al. (2019), por sua vez, ao elaborar uma formulação de brownie funcional sem glúten e sem lactose encontraram para os atributos valores médios variando de 5,94 a 6,54 e índices de aceitabilidade superiores a $80 \%$.

As Figuras 3 e 4 apresentam a frequência com que os provadores consomem brownie e fibras.

Figura 3. Frequência de consumo de brownie pelos participantes.

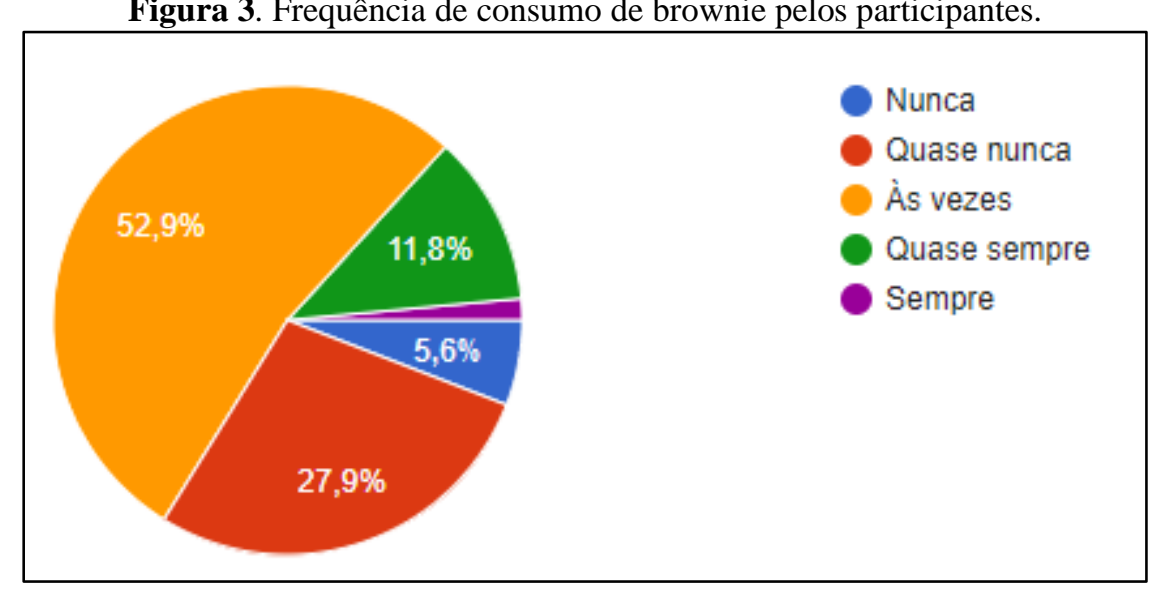

Fonte: Própria (2020). 
Figura 4. Frequência com que os provadores costumam consumir produtos adicionados de fibras.

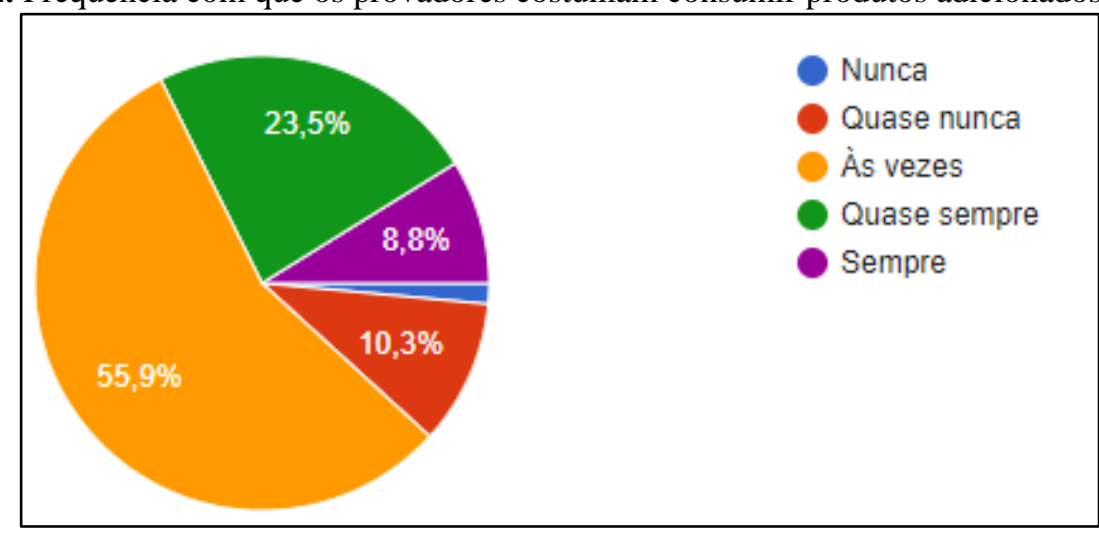

Fonte: Própria (2020).

Foi possível observar um comportamento semelhante de frequência de consumo de brownie e de fibras pelos participantes. Em sua maioria, tanto o consumo de brownie como de fibras é feito ocasionalmente pelos provadores $(52,9 \%$ e 55,9\%, respectivamente, disseram consumir "as vezes"). Isso provavelmente se deve ao fato de que tanto o brownie quanto os produtos adicionados de fibra possuem um valor agregado e, com isso, possuem preços mais elevados, o que limita o consumo ao poder de compra do cliente.

Ainda com relação à pesquisa de mercado, 66,2\% já consumiram alimentos adicionados de um subproduto da fabricação de cerveja, sendo ainda que a maioria desses, são consumidores de cervejas artesanais $(61,8 \%$ dos provadores são consumidores de cerveja e desses, $55,8 \%$ costumam consumir cerveja artesanal). Isso indica que provavelmente as pessoas que consomem cerveja artesanal têm maior interesse em alimentos que sejam fabricados com subprodutos do processo fermentativo e poderiam ser o público-alvo para direcionamento de ações de marketing.

Por fim, a maioria dos participantes apontou a adição de fibras como influenciadora na intenção de compra $(66,2 \%)$ indicando que o produto desenvolvido pode ter um potencial no mercado. Atualmente, como os consumidores se preocupam mais com a saúde, a difusão de conhecimentos sobre informações nutricionais tem crescido e, assim, as preferências dos clientes tem se modificado. Dessa forma, uma determinada característica nutricional que é importante para o consumidor pode ser decisiva no momento de uma escolha entre marcas (BERNARDON; PERIN; SAMPAIO, 2008).

\section{Informação Nutricional}

A informação nutricional do brownie elaborado pode ser observada no Quadro 1:

Foram coletadas informações nutricionais de dois brownies de chocolate de marcas comerciais conhecidas (A e B) que continham ingredientes base semelhantes aos utilizados 
neste trabalho (Quadro 2) com a finalidade de comparação.

Quadro 1. Informação nutricional do brownie elaborado com bagaço de malte.

\begin{tabular}{|c|c|c|}
\hline \multicolumn{3}{|c|}{ Informação Nutricional } \\
\hline \multicolumn{3}{|c|}{ Porção 40 g (1 unidade) } \\
\hline \multicolumn{2}{|c|}{ Quantidade por porção } & $\% \mathrm{VD}(*)$ \\
\hline Valor energético & $125 \mathrm{kcal}=524 \mathrm{~kJ}$ & 6 \\
\hline Carboidratos & $17 \mathrm{~g}$ & 6 \\
\hline Proteínas & $1,7 \mathrm{~g}$ & 2 \\
\hline Gorduras totais & $5,5 \mathrm{~g}$ & 10 \\
\hline Gorduras saturadas & $1,9 \mathrm{~g}$ & 9 \\
\hline Gorduras trans & $0 \mathrm{~g}$ & $* *$ \\
\hline Fibra alimentar & $1,5 \mathrm{~g}$ & 6 \\
\hline Sódio & $48 \mathrm{mg}$ & 2 \\
\hline \multicolumn{3}{|c|}{$\begin{array}{l}\text { (*) \% Valores diários com base em uma dieta de } 2000 \mathrm{kcal} \text { ou } 8400 \mathrm{~kJ} \text {. Seus valores diários } \\
\text { podem ser maiores ou menores dependendo de suas necessidades energéticas. } \\
(* *) \text { VD não estabelecido. }\end{array}$} \\
\hline
\end{tabular}

Fonte: Própria (2020).

Quadro 2. Informação nutricional de dois brownies de chocolate das marcas comerciais A e B.

\begin{tabular}{|c|c|c|c|c|}
\hline \multicolumn{5}{|c|}{ Informação Nutricional } \\
\hline \multicolumn{5}{|c|}{ Porção 40 g } \\
\hline & \multicolumn{2}{|l|}{ Marca A } & \multicolumn{2}{|l|}{ Marca B } \\
\hline & Quantidade por porção & $\% \mathrm{VD}(*)$ & Quantidade por porção & $\% \mathrm{VD}(*)$ \\
\hline Valor energético & $163 \mathrm{kcal}=681 \mathrm{~kJ}$ & 8 & $179 \mathrm{kcal}=752 \mathrm{~kJ}$ & 9 \\
\hline Carboidratos & $21 \mathrm{~g}$ & 7 & $20 \mathrm{~g}$ & 7 \\
\hline Proteínas & $2,1 \mathrm{~g}$ & 3 & $2,1 \mathrm{~g}$ & 3 \\
\hline Gorduras totais & $7,1 \mathrm{~g}$ & 13 & $10 \mathrm{~g}$ & 18 \\
\hline Gorduras saturadas & $2,7 \mathrm{~g}$ & 12 & $5,7 \mathrm{~g}$ & 26 \\
\hline Gorduras trans & $1,2 \mathrm{~g}$ & $* *$ & $0 \mathrm{~g}$ & $* *$ \\
\hline Fibra alimentar & $1,0 \mathrm{~g}$ & 4 & $0,8 \mathrm{~g}$ & 3 \\
\hline Sódio & $168 \mathrm{mg}$ & 7 & $14 \mathrm{~g}$ & 1 \\
\hline
\end{tabular}

Fonte: Própria (2020).

Confrontando as informações apresentadas no Quadro 1 com o Quadro 2, pode-se observar que o brownie desenvolvido neste trabalho apresenta menores valores de carboidratos, proteínas, gorduras totais, gorduras saturadas e valor energético quando comparado às duas marcas comerciais A e B. Tanto o produto da marca B quanto o brownie adicionado de fibra 
de malte não contém gorduras trans. Com relação ao teor de sódio, a formulação desenvolvida possui um menor teor que a marca $\mathrm{A}$, porém maior que a marca B. Por fim, considerando o valor de fibras, o brownie desenvolvido apresenta um maior teor que as duas marcas comerciais, o que provavelmente se deve à presença do bagaço de malte.

\section{Conclusões}

Concluiu-se que é possível elaborar um brownie adicionado de bagaço de malte e obter boas características tecnológicas e sensoriais. O brownie desenvolvido demonstrou baixa acidez, coloração marrom, umidade baixa e apresentou uma boa aceitação sensorial e intenção de compra. Contudo, se o processo de refinamento do bagaço de malte fosse mais minucioso, poderia se alcançar uma maior aceitação do produto com uma textura mais agradável. Assim, a formulação poderia ser aperfeiçoada para se tornar um produto com aceitação ainda maior.

\section{Referências}

ALMEIDA, E. L. Efeito da adição de fibra alimentar sobre a qualidade de pão pré-assado congelado. 2006, 328 f. Dissertação (Mestrado em Tecnologia de Alimentos) - Universidade Estadual de Campinas, Campinas, 2006.

ANVISA. Manual de Orientação às Indústrias de Alimentos. $2^{\circ}$ versão, Brasília: Ministério da Saúde, Agência Nacional de Vigilância Sanitária/Universidade de Brasília, 2005.

BERNARDON, R.; PERIN, M. G.; SAMPAIO, C. H. Influência das Informações Nutricionais na Intenção de Compra do Consumidor de Alimentos. In: XXXII Encontro da ANPAD, 2008, Rio de Janeiro. Anais do XXXII Encontro da ANPAD, 2008.

BRASIL. Comissão Nacional de Normas e Padrões para Alimentos (CNNPA). Aprova Normas Técnicas Especiais, do Estado de São Paulo, revistas pela CNNPA, relativas a alimentos (e bebidas), para efeito em todo território brasileiro. Resolução CNNPA no 12, de 1978. Diário Oficial da União, Brasília, 24 de julho de 1978.

BRASIL. Ministério da Saúde. Aprova o Regulamento Técnico de Porções de Alimentos Embalados para Fins de Rotulagem Nutricional. Resolução RDC ${ }^{\circ}$ 359, de 23 de dezembro de 2003. Diário Oficial da União. Brasília, 26 de dezembro de 2003.

CARVALHO, J. M. A cerveja e a viabilidade tecnológica e nutricional do aproveitamento do resíduo de seu processamento: revisão. 2019. $33 \mathrm{f}$. Trabalho de conclusão de curso de Graduação apresentado ao curso de Engenharia de Alimentos - Universidade Federal de Lavras. Lavras, 2019.

CORDEIRO, L. G.; EL-AOUAR, A. A.; GUSMÃO, R. P. Caracterização do bagaço de malte oriundo de cervejarias. Revista Verde, Mossoró - RN, v. 7, n. 3, p. 20-22, 2012.

COSTA, B. P.; LOURENCO, L. B. V.; Silva, I.D.; Miranda, K. W. E.; ZAMBELLI, R. A.; SOUSA, C.R.V. Perfil sensorial de brownie funcional com farinha de banana verde, enriquecida de nozes e sementes de chia. In: Anais do Simpósio Latino Americano de Ciências 
de Alimentos, 2015, Campinas. Anais eletrônicos do Simpósio Latino Americano de Ciências de Alimentos, 2015.

COSTA FILHO, D. V.; SILVA, A. J.; SILVA, P. A. P.; SOUSA, F. C. Aproveitamento de resíduos agroindustriais na elaboração de subprodutos. In: II Congresso Internacional das Ciências Agrárias - COINTER - PDVAgro, 2017. Anais do Congresso Internacional das Ciências Agrárias - COINTER - PDVAgro, 2017.

DALMOLIN, C., IENSEN, G., RIBEIRO, J., LOPES, M., \& BASSO, C. Análise sensorial de um brownie sem glúten e sem lactose. Disciplinarum Scientia, Série: Ciências da Saúde, Santa Maria, v. 20, n. 2, p. 295-303, 2019.

DUTCOSKY, S. D. Análise sensorial de alimentos. 3. ed. Curitiba: Champagnat, 2011.

FRANCO, B. D. G. M.; LANDGRAF, M. Microbiologia dos alimentos. São Paulo: Atheneu, 1996.

HERNÁNDEZ, A.; RODRÍGUEZ, J. L.; LOPEZ, B.; ZERQUERA, O. Caracterización química e functional del afrech de malta. Alimentaria, n. 302, p. 105-107, 1999.

INSTITUTO ADOLFO LUTZ - IAL. Normas analíticas do Instituto Adolfo Lutz. 2.ed. São Paulo, v. 4, formato digital, 2008.

KALIL, M. Brownies e cookies têm se mostrado excelente negócio para jovens empreendedores da Capital. Disponível em: https://gauchazh.clicrbs.com.br/donna/noticia/2015/11/brownies-e-cookies-tem-se-mostradoexcelente-negocio-para-jovens-empreendedores-da-capital-cjplhzrpz003bh9cn0uco0535.html. Acesso em: 25 maio 2020.

LISBOA, A. P. Doceira apresenta excelência na gestão e nos brownies. Disponível em: https://www.correiobraziliense.com.br/app/noticia/eu-estudante/trabalho-e-

formacao/2017/09/17/interna-trabalhoeformacao-2019,626708/doceira-apresenta-excelenciana-gestao-e-nos-brownies.shtml. Acesso em: 25 maio 2020.

MATTOS, C. Desenvolvimento de um pão fonte de fibras a partir do bagaço de malte. 2010. 40 f. Monografia (Graduação em Engenharia de Alimentos) - Universidade Federal do Rio Grande do Sul, Porto Alegre, 2010.

MOURA, K. L. A.; MOURA, S. I. A. Desenvolvimento e avaliação das características nutricionais, físico-químicas e sensoriais de bolo com diferentes tipos de farinhas e Castanha-do-Brasil (Bertholletia excelsa HBK). 2014. 65 f. Monografia (Bacharelado em Engenharia de Alimentos) - Fundação Universidade Federal de Rondônia, Ariquemes, 2014.

ORSINE, J. V. C.; MARTINS, L. F.; LIMA, K., K., B. Caracterização físico-química e microbiológica de brownie de chocolate utilizando-se ingredientes dietéticos, light e não dietéticos. Revista Brasileira de Tecnologia Agroindustrial, v. 10, n. 2, p. 2053-2068, 2016. PADIA, M. L. B. Cookie funcional com bagaço de malte uma nova proposta quando comparado ao industrializado. 2018. 61 f. Monografia (Bacharelado em Nutrição) Universidade Regional do Noroeste do Estado do Rio Grande do Sul - Unijuí, Ijuí, 2018.

PANZARINI, N. H.; RABBERS, A.; DA TRINDADE, J. L. F., DE MATOS, E. A. S. A., CANTERI, M. H. G., \& BITTENCOURT, J. V. M. Elaboração de bolo de mel enriquecido 
com fibras do bagaço da indústria cervejeira. Revista Brasileira de Tecnologia Agroindustrial, v. 8, n. 1, p. 1154-1164, 2014.

QUEIROZ, M. P.; COSTA A., C., S.; CARVAlHO C., U., S.; CAVAlCANTI, M., S., J.; SOARES, K., B. Avaliação das características físico-químicas de brownies produzidos a partir de farinha de coco e farinha de arroz. In: ONE, G. M. C.; CARVALHO, A. G. C. Nutrição e Saúde: conhecimento, integração e tecnologia 1. João Pessoa: Impressos Adilson, 2016, p. 98-110.

SANTIAGO, B. A expansão do brownie. Disponível em: https://www.argosjr.com/expansaodo-brownie/. Acesso em: 25 maio 2020.

SANTOS, J. I.; DINHAM, R. O essencial em cervejas e destilados. São Paulo: Senac, 2006. $135 \mathrm{p}$.

SEBRAE. Empresários apostam no brownie como oportunidade de negócio. Disponível em: https://www.sebrae.com.br/sites/PortalSebrae/ufs/se/noticias/empresarios-apostam-nobrownie-como-oportunidade-de-

negocio,3b4a2586d3e02510VgnVCM1000004c00210aRCRD. Acesso em: 25 maio 2020.

SCHMIELE, M.; DA SILVA, L. H., DA COSTA, P. F. P., RODRIGUES, R. D. S.; CHANG, Y. K. Influência da adição de farinha integral de aveia, flocos de aveia e isolado proteico de soja na qualidade tecnológica de bolo inglês. Boletim do Centro de Pesquisa de Processamento de Alimentos, v. 29, n. 1, p. 71-82, 2011.

SILVA, J. Y. P.; SILVA, A. R.; DOMINGOS, L. B. S.; MARTINS, A. C. S.; OLIVEIRA, M. E. G. Avaliação da aceitação sensorial de brownie elaborado com farinha de berinjela (Solanum melongena L.) e soro de leite caprino. In: II Congresso Brasileiro de Ciências da Saúde, 2017, Campina Grande. Anais do II Congresso Brasileiro de Ciências da Saúde, 2017.

SIMON, A. Elaboração de brownie sem glúten com a utilização de farinha de arroz e trigo sarraceno. 2014. $71 \mathrm{f}$. Trabalho de conclusão de curso de Graduação apresentado ao curso de Engenharia de Alimentos - Universidade Federal do Rio Grande do Sul. Porto Alegre, 2014. 